\title{
Effects of different salinity levels on larval growth and development of disease vectors of Culex species
}

Paper received: 23.06.2018 Revised received: 16.11.2018 Re-revised received: 23.01.2019 Accepted: 17.04.2019

\section{Authors Info \\ R. Balasubramanian*, S. Sahina, V. Arathy Nadh, K.P. Sreelekha and T.L. Nikhil \\ National Institute of Virology-Kerala Unit, Alappuzha-688 005, India}

${ }^{*}$ Corresponding Author Email : balasniv@gmail.com

\section{Edited by \\ Dr. Mukesh K. Dhillon}

\section{Reviewed by}

Dr. Tushar Kanti Mukherjee

Dr. Sumati Gaumat

\section{Abstract}

Aim : To determine species distribution of mosquitoes in coastal brackish wetlands and in paddy field area of Kerala along with the effect of increased salinity on the development and survival of major Japanese encephalitis vectors.

\begin{abstract}
Methodology : Mosquito survey was carried out in different sites of coastal brackish water as well as in paddy fields of Alappuzha district. First instar larvae were reared until adult emergence at different constant saline water. Each individual was monitored daily for mortality. Larvae were placed in a plastic container with $200 \mathrm{ml}$ distilled water, which served as controls. Counts of larvae, pupae and adults were recorded every $24 \mathrm{hr}$ up to adult emergence.
\end{abstract}

Results : The collected mosquitoes were Culex tritaeniorhynchus, Cx. gelidus, Cx. sitiens, $C x$. quinquefasciatus, $C x$. bitaeniorhynchus and Anopheles vagus. During summer season, Cx. sitiens $(92.85 \%)$ was the predominant species followed by $\mathrm{Cx}$. tritaeniorhynchus $(2.97 \%)$ and $C x$. gelidus $(2.25 \%)$. In

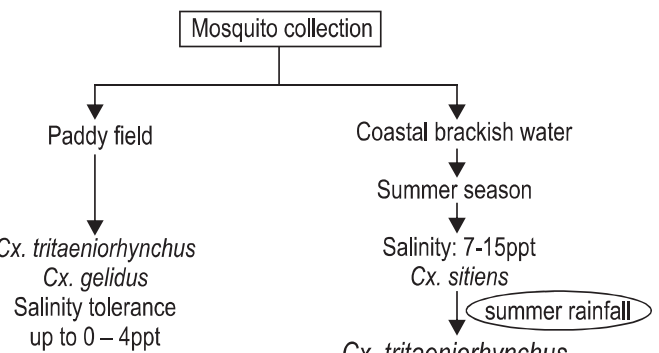
up to $0-4$ pet $0-4 \mathrm{ppt}$

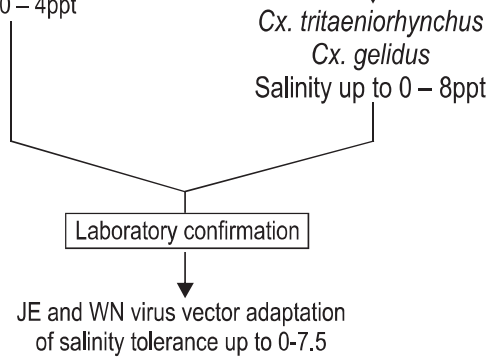

saline tolerant study, the maximum adult emergence occurred at 5 parts per thousand. The number of larvae surviving till adult stage decreased progressively with increased salinity. The wing size decreased significantly with increasing salinities, except those reared in $5 \mathrm{ppt}$.

Interpretation : The present study demonstrates that these three mosquitoes have the ability to oviposit and breed in brackish water. The study also reveals the health risks associated with vector mosquitoes developing and their frequency of abundance in brackish water, particularly in the context of rising sea levels due to global warming.

Key words: Brackish water, Culex mosquito, Japanese encephalitis, Salinity levels

How to cite : Balasubramanian, R., S. Sahina, V.A. Nadh, K.P. Sreelekha and T.L. Nikhil: Effects of different salinity on larval growth and developmental of disease vectors of Culex mosquito species (Diptera: Culicidae). J. Environ. Biol., 40, 1115-1122 (2019). DOI: http://doi.org/10.22438/eb/40/5/MRN-950 


\section{Introduction}

Coastal brackish water is among the most common and productive mosquito larval habitats on earth. These habitats are also important for public health worldwide as immature habitats for disease-vector mosquitoes (Leisnham and Mohapatra, 2011; Van Schie et al., 2009; Medlock et al., 2005; James et al., 2011 and Becker et al., 2003). Mosquito species that breed in salt marshes along the Arabic coast of Kerala can be a considerable nuisance to humans and are likely to vary in their importance in transmitting a range of arboviruses, including Japanese encephalitis virus (JEV) (family Flaviviridae, genus Flavivirus) and West Nile virus (WNV) (family Flaviviridae, genus Flavivirus). Japanese encephalitis is a mosquito borne zoonotic pathogen, native to Asian countries, which has a significant human disease burden; approximately 30000-50000 human cases per year (Daniel et al., 2011). The major vectors of Japanese encephalitis are Culex mosquitoes, of which Culex tritaeniorhynchus is considered to be the primary vector throughout Southeast Asia (Vaughn and Hoke, 1992). In India, the case of Japanese encephalitis was first reported in 1955 (Kanojia and Jamgaonkar, 2008); subsequently, many epidemics have occurred in different parts of the country. Japanese encephalitis and West Nile virus complex outbreak in the coastal belt of Alappuzha district, Kerala in 2011 , caused $50-75 \%$ mortality from encephalitic infections, making it the most severe insect-borne disease in Alappuzha district. Rice fields are the preferred development sites for $\mathrm{Cx}$. tritaeniorhynchus as well as the main foraging site for water birds; thus rice fields provide an important site for birds and mosquitoes to meet.

The projected climate change scenario estimates that the atmospheric temperature across Kerala will rise by $2^{\circ} \mathrm{C}$ by the year 2050 (Source: Department of Environment and Climate change, Govt. of Kerala). Also, it is estimated that if the sea level rises by one meter, $169 \mathrm{~km}^{2}$ of the coastal region would be inundated. The coastal line of Kerala is $590 \mathrm{~km}$ in length, in which, the maximum coastline is shared by Alappuzha district $(82 \mathrm{~km})$. Alappuzha is listed as highly vulnerable to climate change because of interconnected brackish canals, estuaries, sensitive wetlands, salt marshes, lakes and rivers. Less rainfall subsequently reduces river water inflow into the lagoons and rising sea level are responsible for the cause of salinity in backwaters (Padmakumar, 2013). Due to saline water intrusion into the paddy field and inland area saline tolerant mosquitoes have increased in Alappuzha district (Balasubramanian and Nikhil, 2015). Population of mosquitoes are known to respond to a range of environmental conditions, including disturbance, which can have direct or indirect effects on their colonization (Padmakumar, 2013 and Asigau and Parker, 2018).

Over the past several decades, Kerala has experienced population increase along the coastal area. During population increase, coastal area typically experience infrastructure development like fishing harbour, urbanization, land use changes and associated decay that can significantly alter the biotic environment (Sundaresan and Patel, 2011; Baruah et al., 2004). Therefore, the change of environmental conditions may have direct or indirect effect on disappearance of some species as well as reappearance or introduction of new species (Dutta et al., 2010). These environmental disturbances are associated with the appearance of emergence and re-emergence of mosquito-borne disease including Japanese encephalitis, West Nile, dengue and chikungunya virus, has increasingly been associated with coastal landscapes. Hence, in view of the above, in this study, we examined association between saline disturbance, aquatic environment, and the direct and indirect ecological consequences of this climate disturbance to mosquito distribution and also laboratory studies were carried out to determine the effect of increased salinity on the development of three major encephalitis vectors.

\section{Materials and Methods}

Larval mosquito sampling: A total of five study sites were selected from Alappuzha district on the basis that they represented important roosting or foraging sites for herons and egrets and that there were known potential mosquito habitats, i.e., ephemeral or permanent wetlands and rice fields in the nearby area. Mosquito larval collections were conducted from coastal and paddy field locations (Fig. 1) in a bimonthly interval from December 2016 to May 2017, which is the peak time of mosquito activity. The coastal sites such as Thottappally ( $\mathrm{N}$ $09^{\circ} 18^{\prime} 51.5^{\prime \prime}-\mathrm{E} 076^{\circ} 22^{\prime} 58.1^{\prime \prime}$ ), Chethy (N 09 $37^{\prime} 25.5^{\prime \prime}$ - E0 $\left.76^{\circ} 17^{\prime} 45.6^{\prime \prime}\right)$ and Vadackal (N 09 $27^{\prime} 25.6^{\prime \prime}-$ E0 76 $6^{\circ} 19^{\prime} 36.1^{\prime \prime}$ ) and

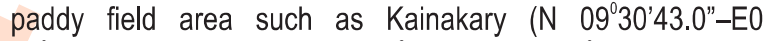
$76^{\circ} 21^{\prime} 14.8^{\prime \prime}$ ) and Thakazhy (N 09 $\left.26^{\prime} 13.4^{\prime \prime}-\mathrm{E} 076^{\circ} 25^{\prime} 40.6^{\prime \prime}\right)$ were selected. Larval mosquitoes were sampled in a $350 \mathrm{ml}$ capacity enamel metal dipper and mosquito production quantified using standard dip count method with densities expressed in numbers per dip. During each collection, ephemeral and permanent ponds in salt marsh sites and margin of rice field areas were sampled for 10 dips per site. Six-permanent ponds and thirteen ephemeral pools were used. The collected larvae were brought to laboratory. They were counted, and $3^{\text {rd }}$ and $4^{\text {th }}$ instar larvae were reared to adults, which were identified morphologically using standard taxonomic keys.

Seawater experiment : Blood fed mosquitoes were collected form field because only blood fed mosquitoes are able to lay eggs and thereby we can collect egg rafts. They were maintained until eclosion in individual plastic containers with dechlorinated tap water. Within $12 \mathrm{hr}$ of eclosion, 50 newly hatched first instar larvae were randomly selected from each raft and individually placed in labeled plastic cups ( $3 \mathrm{~cm}$ diameter; $5 \mathrm{~cm}$ height) containing 200 $\mathrm{ml}$ different concentration of saline water. They were reared until adult emergence from the following constant saline water: $5,7.5$, $10,12.5,15,17.5$ and 20 ppt of saline water (Schie et al., 2009; Zalizniak et al., 2006). Three replications were maintained for each set of experiment. Salinity was measured with a Hand Held Refractometer (Atago Co. Ltd, Japan). The larvae were fed daily 
with fish feed (it contains all the necessary nutrients required for growth of mosquito larvae) until all the larvae either pupated or died. Each individual was monitored daily at the same hour to record larval stage, moulting, mortality or date of imago emergence. Larvae also placed in a plastic container with $200 \mathrm{ml}$ of distilled water, served as controls for the experiment. When the larvae pupated, the containers were covered with mosquito-proof mesh. Counts of larvae, pupae and adults were recorded every $24 \mathrm{hr}$. Dead larvae and pupae were removed and counted daily to calculate the average mortality rate for each salinity concentration.

Adult mosquitoes from each salinities were collected separately and killed by freezing $\left(-20^{\circ} \mathrm{C}\right)$ after emergence. Afterwards, each specimen was examined under an Axioskop 40 compound microscope with ProgRes ${ }^{\text {TM }} \mathrm{C} 10^{\text {Plus }}$ software analysis. Wing length, measured from the base of the costal vein to distal extreme of R3 vein excluding the fringe setae, was used as an indicator of imaginable body size (Clements, 1992).

Data analyses: The measured wing length was statistically analyzed with the help of IBM Corp. SPSS Statistics 20 software. One way ANOVA was run to determine the relationship between mosquito body size and salinity.

\section{Results and Discussion}

The present study revealed that several mosquito vectors in coastal areas of Kerala can undergo pre-imaginal development in brackish water bodies. Mosquito larvae and pupae were collected along the coastal brackish water bodies that had salinity levels up to 0-15 ppt and paddy field area (with salinity level ranging from 0-4ppt) at different times (Fig. 5). Immature stages of Culex species inhabit sunlit stagnant water, including small pits, pit lakes, wells, swamps, ponds, canals and paddy fields.

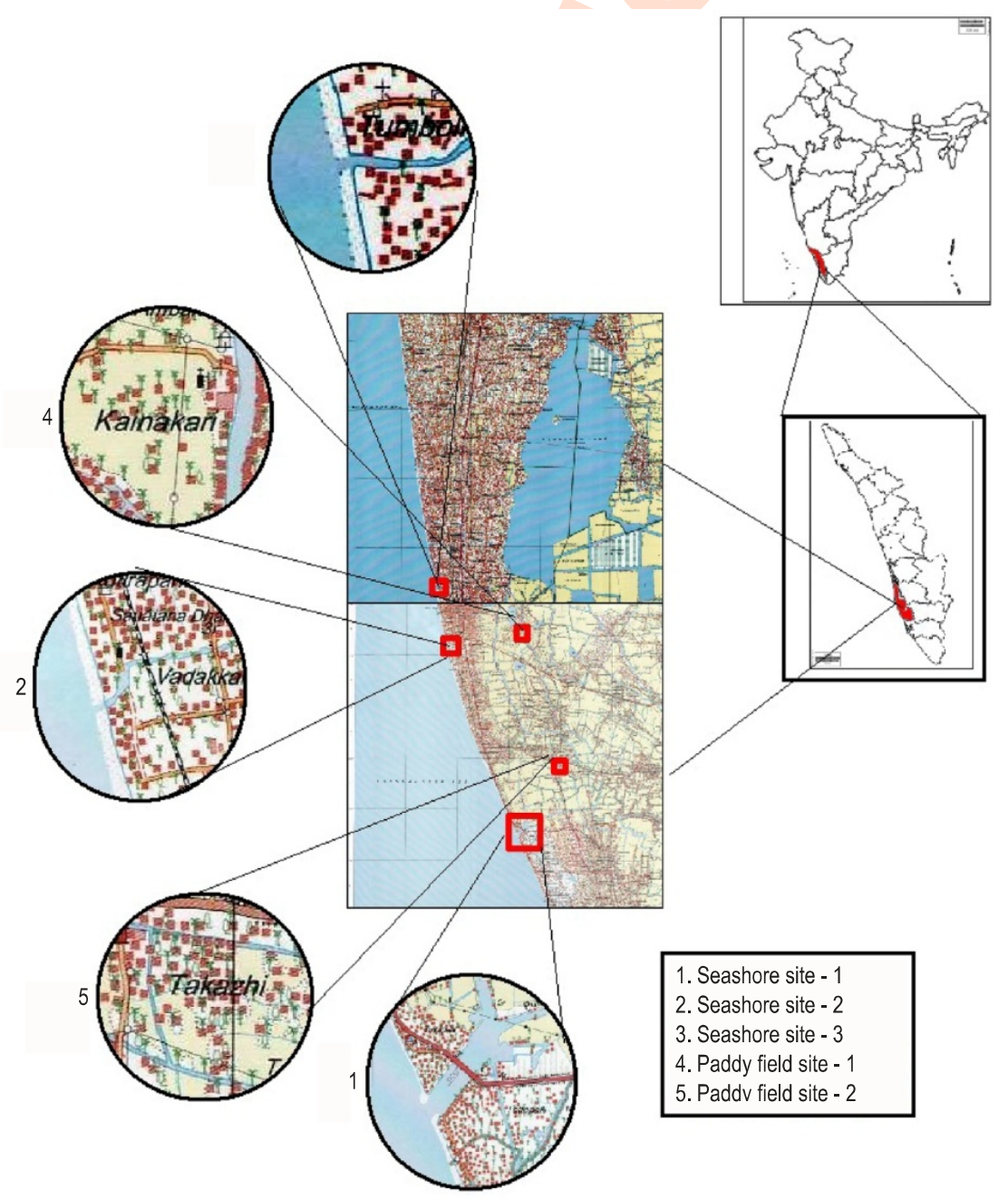

Fig. 1: Mosquito collection sites in Alappuzha district are highlighted in circles which include three experiments and two control sites. 


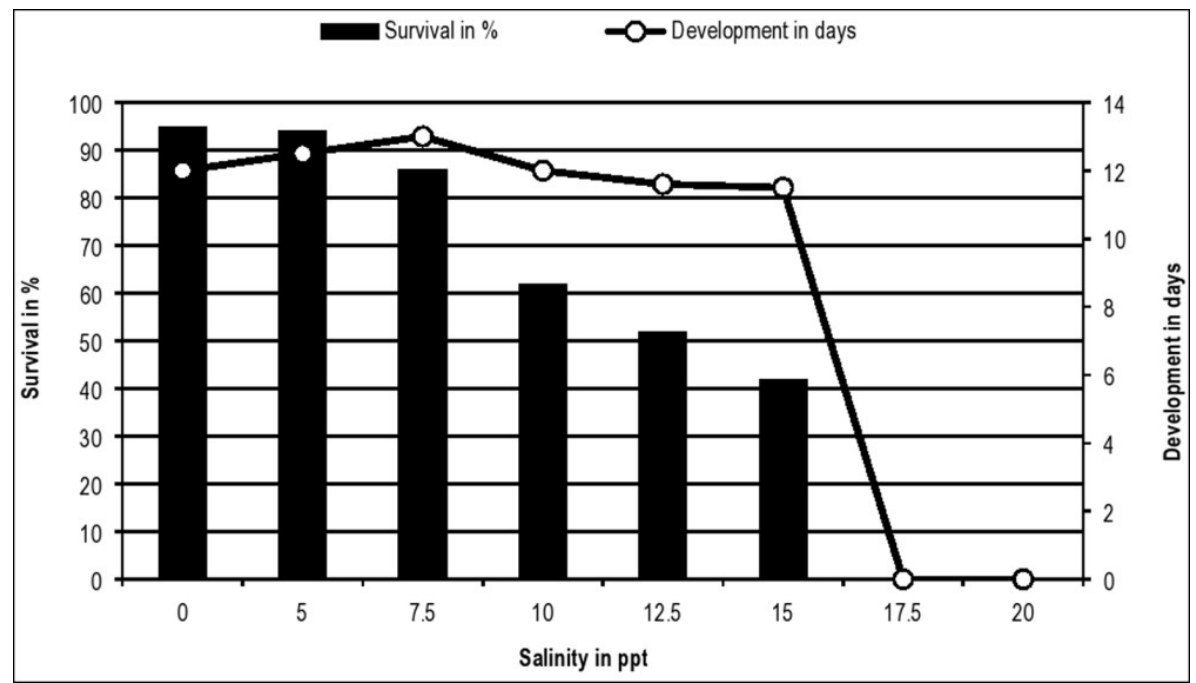

Fig. 2: Survival rate and development in days of $C x$. tritaeniorhynchus.

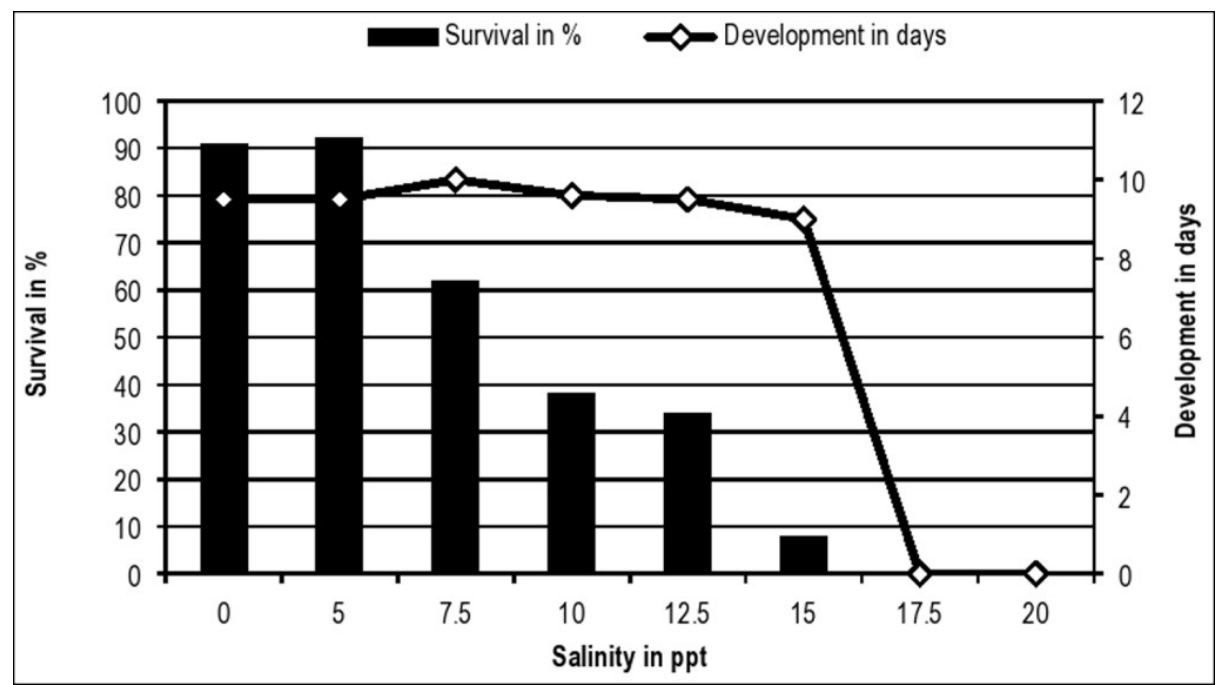

Fig. 3 : Survival rate and development in days of $C x$. quinquefasciatus.

Water was contaminated with bird feces, floating pieces of dried leaves, filamentous green algae and grasses. Larvae were abundant in permanent pond as compared to ephemeral pools. There did not seem to be any species separation between different pool types. However, during summer season in permanent water ponds only $C x$. sitiens was observed. Mosquito species such as $C x$. tritaeniorhynchus, $C x$. gelidus, $C x$. quinquefasciatus, $C x$. sitiens, Anopheles peditaeniatus and
An. vagus were collected from both permanat ponds and ephemeral pools after the onset of summer rainfall.

Mosquitoes such as $C x$. sitiens (sea shore) and Cx. tritaeniorhynchus (paddy field) was the most abundant species, accounting for nearly half of the collections, peaking in March to May in coastal areas and throughout the year in paddy fields. A total of 21605 individuals of mosquito immature stages 


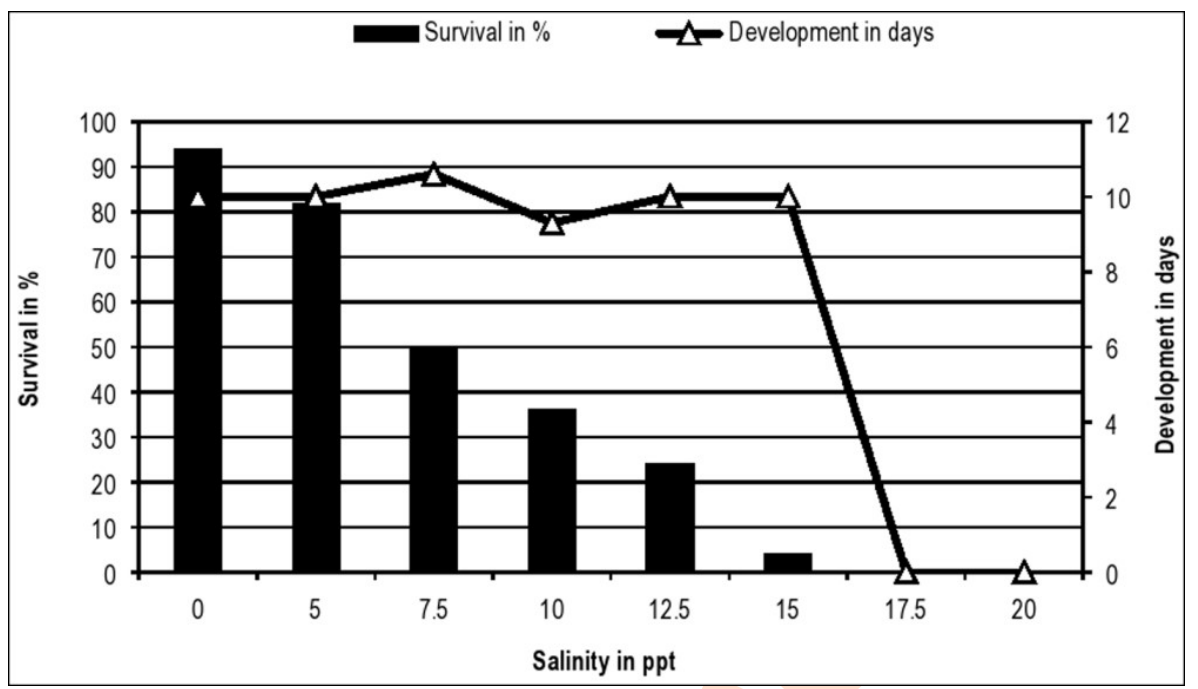

Fig. 4 : Survival rate and devlopment in days of $C x$. gelidus.

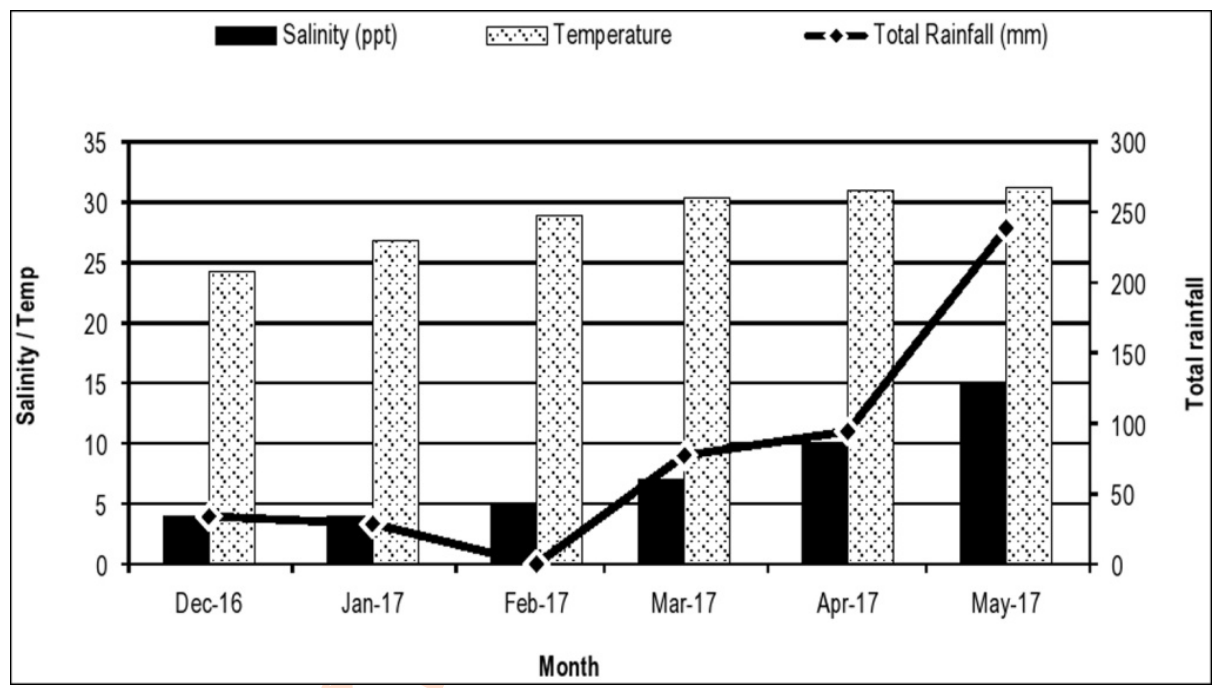

Fig. 5 : Monthwise climate data (temperature, salinity and rainfall) of Alappuzha district from Dec-16 to May-1.

representing eight mosquito species were collected. Collected immature were reared in laboratory and emerged adult were identified as Anopheles vagus, Cx. sitiens, Cx. tritaeniorhynchus, $C x$. gelidus and $C x$. bitaeniorhynchus, (Table 1). In sea shore area, Cx. sitiens was predominant species and a total of 15057 (92.85\%) individuals of immature stages were collected, it was restricted almost entirely in estuary areas. Cx. sitiens was absent following the onset of summer rain during early May. However, in the same pond $C x$. sitiens mosquito was replaced by $C x$. tritaeniorhynchus and salinity of pond reduced to zero. The second predominant species was $C x$. tritaeniorhynchus $(2.97 \%$ followed $C x$. gelidus $(2.25 \%)$. Other species were consistently observed more frequently and in moderate densities from nearby salt marsh ground pools and rice fields (Table 2). Similarly, different species 
Table 1: Total number and percentage of different mosquito species collected from paddy fields and seashore

\begin{tabular}{|c|c|c|c|c|c|c|c|c|c|}
\hline \multirow{2}{*}{ Mosquito species } & \multicolumn{2}{|c|}{ Paddy field } & \multirow{2}{*}{\multicolumn{2}{|c|}{ Total percentage }} & \multicolumn{3}{|c|}{ Seashore } & \multirow[b]{2}{*}{ Total } & \multirow[b]{2}{*}{ Percentage } \\
\hline & Site 1 & Site 2 & & & Site -1 & Site -2 & Site -3 & & \\
\hline Anopheles peditaeniatus & 127 & 54 & 181 & 3.35 & 4 & 0 & 54 & 58 & 0.35 \\
\hline An. barbirostris & 7 & 2 & 9 & 0.16 & 15 & 25 & 0 & 40 & 0.24 \\
\hline An. vagus & 0 & 0 & 0 & 0 & 8 & 18 & 24 & 50 & 0.30 \\
\hline Culex bitaeniorhynchus & 12 & 55 & 67 & 1.24 & 18 & 72 & 3 & 93 & 0.57 \\
\hline Cx. fuscanus 5 & 9 & 14 & 0.25 & 4 & 12 & 54 & 70 & 0.43 & \\
\hline Cx. gelidus & 188 & 275 & 463 & 8.59 & 57 & 152 & 157 & 366 & 2.25 \\
\hline Cx. sitiens & 8 & 5 & 13 & 0.24 & 14475 & 57 & 525 & 15057 & 92.85 \\
\hline Cx. tritaeniorhynchus & 2257 & 2385 & 4642 & 86.13 & 327 & 0 & 155 & 482 & 2.97 \\
\hline Total & 2604 & 2785 & 5389 & & 14908 & 336 & 972 & 16216 & \\
\hline
\end{tabular}

*As Cx. quinquefasciatus mosquito was collected from discarded fishing boat and plastic containers, the data was omitted from this table

showed different densities in different months. Regarding the time of collection, larvae occurred more often and higher densities during summer season. During summer season, drought created more stagnant pools that are ideal breeding ground for salt marsh mosquitoes (Yoruk et al., 2018; Jemi and Hatha, 2018). Salt marshes are also important for public health worldwide as larval habitats for disease-vector mosquitoes and significant biting pests (Schie et al., 2009). Cx. sitiens is often the most common Culex mosquito present in salt marshes and has been collected from costal salt marshes at salinities ranging from 10 to $66 \%$ of sea water in previous studies (Ray and Chaudhary, 1988). Onset of summer rainfall in the month of May changes existing salt marshes and associated mosquito species. This unseasonal heavy rainfall causes flooding and decreases the population of saline tolerant-vectors by eliminating suitable larval habitats and creating unsuitable environments for such vectors (Luis et al., 2019). Alternatively, intrusion of fresh water may turn former salt marsh habitats into fresh-water areas and alter abiotic factors, such as salinity and biotic factors, such as food resources and predators which could support Cx. tritaeniorhynchus, vector species of Japanese encephalitis. Increasing abundance of these mosquitoes can have important human health implications since these mosquitoes are aggressive biters of both birds and humans and thus can act as bridge vectors for encephalitis viruses in the surrounding area.

Irrigation of rice fields is usually accomplished by flooding, and water persists at a depth $20-30 \mathrm{~cm}$ for few months during summer season. This persistence of water and

Table 2 : Larval mosquitoes observed along the coastal area of Alappuzha district during study period

\begin{tabular}{|c|c|c|c|c|c|c|}
\hline Mosquito species & $\begin{array}{l}\text { Medical } \\
\text { significance }\end{array}$ & $\mathrm{pH}$ & $\begin{array}{l}\text { Distance from } \\
\text { seashore }(m)\end{array}$ & Nature of habitat & $\begin{array}{l}\text { Average larval } \\
\text { number per } \\
\text { site in } 350 \mathrm{ml} \mathrm{dip}^{-1}\end{array}$ & $\begin{array}{l}\text { Salinity range } \\
\text { of habitat with } \\
\text { larvae (ppt) }\end{array}$ \\
\hline $\begin{array}{l}\text { Anopheles } \\
\text { barbirostris }\end{array}$ & Malaria & 8.2 & 90 & Pond & $1-2$ & $0-5$ \\
\hline An. subpictus & Malaria & 7.2 & 90 & Pond & $2-5$ & $0-1$ \\
\hline An. vagus & Malaria & 8.3 & 90 & Pond & $2-4$ & $5-15$ \\
\hline $\begin{array}{l}\text { Culex } \\
\text { bitaeniorhynchus }\end{array}$ & $\begin{array}{l}\text { Wuchereria } \\
\text { Bancrofti }\end{array}$ & 7 & 90 & Paddy/ Pond & $2-5$ & $0-5$ \\
\hline Cx. fuscanus & Predator & 7.8 & 90 & Stream and pond & $2-4$ & $0-5$ \\
\hline CX. gelidus & $\begin{array}{l}\text { Japanese } \\
\text { Encephalitis }\end{array}$ & 7.8 & 90 & Paddy/ Pond & $5-25$ & $0-5$ \\
\hline Cx. quinquefasciatus & Filariasis & 7 & 135 & Plastic box, pool & $5-10$ & $0-1$ \\
\hline Cx. sitiens & Rose river & 3.3 & 135 & Pond, salt marsh & $>100$ & $10-15$ \\
\hline Cx. tritaeniorhynchus & $\begin{array}{l}\text { Japanese } \\
\text { Encephalitis }\end{array}$ & 6.8 & 135 & Paddy/ Pond & $>100$ & $0-4$ \\
\hline Cx. vishnui & $\begin{array}{l}\text { Japanese } \\
\text { Encephalitis }\end{array}$ & 8 & 135 & Pond & $2-3$ & $0-4$ \\
\hline
\end{tabular}


Table 3: Average wing length of mosquitoes reared at different salinity levels

\begin{tabular}{lllll}
\hline \multirow{2}{*}{$\begin{array}{l}\text { Salinity of } \\
\text { water in ppt }\end{array}$} & Wing type & Wing length & \\
\cline { 3 - 5 } & & Cx. quinquefasciatus $(\mathbf{m m})$ & Cx. tritaeniorhynchus $(\mathbf{m m})$ & Cx. gelidus $(\mathbf{m m})$ \\
\hline Control & & & $3.63 \pm 0.14$ \\
0.00 & Right wing & $4.25 \pm 0.34$ & $3.79 \pm 0.19$ & $3.64 \pm 0.17$ \\
& Left wing & $4.36 \pm 0.33$ & $3.66 \pm 0.20$ & $3.35 \mathrm{c} \pm 0.44$ \\
5.00 & Right wing & $4.21 \mathrm{~b} \pm 0.24$ & $3.51 \mathrm{c} \pm 0.15$ & $3.28 \pm 0.47$ \\
& Left wing & $4.3 \pm 026$ & $3.46 \pm 0.08$ & $3.10 \mathrm{c} \pm 0.26$ \\
7.50 & Right wing & $3.97 \mathrm{a} \pm 0.68$ & $3.64 \mathrm{c} \pm 0.09$ & $3.20 \pm 0.22$ \\
& Left wing & $3.91 \pm 0.59$ & $3.70 \pm 0.15$ & $3.20 \mathrm{c} \pm 0.26$ \\
10.00 & Right wing & $3.53 \mathrm{~b} \pm 0.62$ & $3.53 \mathrm{c} \pm 0.15$ & $3.23 \pm 0.31$ \\
& Left wing & $3.56 \pm 0.65$ & $3.45 \pm 0.06$ & $3.43 \mathrm{c} \pm 0.17$ \\
12.50 & Right wing & $3.5 \mathrm{a} \pm 0.39$ & $3.34 \mathrm{c} \pm 0.10$ & $3.53 \pm 0.20$ \\
& Left wing & $3.52 \pm 0.30$ & $3.32 \pm 0.15$ & $3.17 \mathrm{c} \pm 0.25$ \\
\end{tabular}

a : Highly significant $(\rho=0.001) ; b$ : Significant $(\rho=0.05) ; c$ : Not significant

emergent rice plants provide good habitat for a number of mosquito species, particularly Culex (Zhang et al., 2018). As a result, the percentage of $C x$. tritaeniorhynchus $(86.13 \%)$ and Cx. gelidus $(8.59 \%)$ increased with repeated intermittent irrigation. Japanese encephalitis in Kerala is considered to be mainly transmitted by $C x$. tritaeniorhynchus and the occurrence of disease is associated with rice cultivation with a high incidence reported from the inland of Kuttanad region of Alappuzha (Arunachalam et al., 2009; Thenmozhi et al., 2013). Cx. gelidus is highly zoophagic and poorly anthropophagic; therefore, it may have an important role in amplifying JEV transmission (Hurk et al., 2001; Chathuranga et al., 2018).

High survival percentages are observed in three species (Cx. tritaeniorhynchus, Cx. gelidus and Cx. quinquefasciatus) following hatching when placed in saline water ranging from $5 \mathrm{ppt}$ to $7.5 \mathrm{ppt}$, while larvae of all species always died when placed instead into waters of 20 or 25 ppt salinity (Fig. 1, 2 and 3). All mosquito larvae surviving up to adult stage decreased progressively with increased salinity. Among three mosquitoes reared, Cx. tritaeniorhynchus showed highest survival rate at all salinities, except 20 ppt. More than $50 \%$ of pupae developed into adults up to $7.5 \mathrm{ppt}$ of all mosquitoes. Larvae reared at 15 and 20 ppt showed high mortality in $1^{\text {st }}$ instar stage (the mean larval age at death was 2 days). In contrast, larval mortality occurred in water of lower salinity around the time of pupation. Fresh water mosquito $C x$. quinquefasciatus, is a known vector of West Nile virus and filariasis. Although Cx. quinquefasciatus, is recognized as a fresh water mosquito it was detected for the first time in brackish water and also in laboratory experiments this species showed tolerance at lower salinity level.

All three mosquito species survived best in lower salinities (5 ppt) than higher salinities (>7.5 ppt). Ramasamy and
Surendran (2012) reported Cx. tritaeniorhynchus breeding in sea water in Srilanka and Ray and Choudhury (1988) similarly found maximum $C x$. tritaeniorhynchus survival in laboratory experiments in $18 \mathrm{ppt}$ saline water. Cx. quinquefasciatus survived well in brackish water, with $92 \%$ survival in 5 ppt saline water. Ramasamy et al. (2011) found that Cx. quinquefasciatus in field survived equally well in salinity up to $7 \mathrm{ppt}$ and some survived at 14 ppt also. The developmental mechanism of these species in brackish water is presently unknown and a matter for future investigation. Further, this study has laid the foundation to identify specific genetic and physiological mechanisms underlying salt water tolerance.

In order to evaluate the effect of different salinity levels on mosquito morphology, measured wing length of all mosquitoes reared in different saline water were analyzed. For $C x$. quinquefasciatus, there was a statistically significant difference between wing length of mosquito obtained from control with that of 7.5ppt $(F=1935.68, d f=17, \rho=0.001$, 10ppt $(F=37.69, d f=17, \rho=0.026), 12.5 p p t(F=1007.46, d f=$ 17, $\rho=0.001)$ and 15ppt $(F=75.68, d f=17, \rho=0.013)$, respectively (Table 3 ). Kerala has high population density along the coastal villages with equally high density of shallow coastal aquifers. Higher vector densities can increase transmission of vector-borne diseases. In the present study, it was found that the potential vector of Japanese encephalitis virus $C x$. tritaeniorhynchus can breed and develop in brackish water.

\section{Acknowledgment}

Authors are grateful to the Director, National Institute of Virology, Pune, for his support and encouragement, Dr. MD Gokhale, National Institute of Virology, Pune for critical review of 
the article and for valuable suggestions. The authors also acknowledge the Science and Engineering Research Board (Department of Science and Technology) for financial support ProjectNo.EEQ/2016//0006

\section{References}

Arunachalam, N., U.S.N. Murty, D. Narahari, A. Balasubramanian, P.S. Philip and V. Thenmozhi: Longitudinal studies of Japanese encephalitis virus infection in vector mosquitoes in Kurnool District, Andhra Pradesh, South India. J. Medical Entomo., 46, 633-639 (2009).

Asigau, S. and P. G. Parker: The influence of ecological factors on mosquito abundance and occurrence in Galapagos. J. Vector Ecol., 43, 125-137 (2018).

Balasubramanian, R. and T.L. Nikhil: Effects of rainfall and salinity increase on the production of local vector mosquitoes (Diptera: Culicidae) in coastal areas of Alappuzha District, Kerala. J. Environ. Biol., 36,1325-1328 (2015)

Baruah, I., N.G. Das and S.C. Das: Studies of Anopheline fauna and malaria incidence in Dhansiripar PHC of Dimapur, Nagaland. $\mathrm{J}$. Vector Borne Dise., 41, 67-71 (2004)

Becker, N., D. Petric, M. Zgomba, C. Boase, C. Dahl, J. Lane and A. Kaiser: Mosquitoes and their control. Kluwer Academic/Plenum Publishing, New York (2003).

Chathuranga, W.G.D., S.H.P.P. Karunaratne, B.R. Fernando and W.A. Priyanka P. De Silva: Diversity, distribution, abundance and feeding pattern of tropical ornithophilic mosquitoes. J. Vector Ecol., 43, 158-167 (2018).

Corp. IBM SPSS Statistics for Windows, Version 20.0. Armonk, NY: IBM Corp (2011).

Daniel, E.I., T. Solomon, W. William Schluter, A. Rayamajhi, R. P. Bichha, G. Shakya, C. Caminade and M. Baylis: The spatial heterogeneity between Japanese encephalitis incidence distribution and environmental variables in Nepal. PLoS ONE, 6, 22-192 (2011)

Dutta, P., S.A. Khan, A.M. Khan, C.K. Sharma and J. Mahanta: Survey of mosquito species in Nagaland, a hilly state of north east region of India. J. Environ. Biol., 31, 781-785 (2010)

Hurk, A.F., D.J. Nisbet, C.A. Johansen, P.N. Foley, S.A. Ritchie and J.S. Mackenzie: Japanese encephalitis on Badu Island, Australia: The first isolation of Japanese encephalitis virus from Culex gelidus in the Australian region and the role of mosquito host feeding patterns in virus transmission cycles transactions of the royal society. Tropical Medic. Hygi., 95, 595-600 (2001)

James-Pirri, M.J., R.M. Erwin, D.J. Prosser and J.D. Taylor: Responses of salt marsh ecosystems to mosquito control management practices along the Atlantic coast(USA). Rest. Ecol., 19, 395-404 (2012)

Jemi Job, N. and A.A.M. Hatha: Seasonal variation of copepod community structure in Chavara coast along the Southern Kerala, India. J. Enviro. Biol., 39, 149-158 (2018)

Kanojia, C. and P.V Jamgaonkar: Mosquito records from a hot and dry climatic area experiencing frequent outbreaks of Japanese encephalitis, Bellary District, Karnataka, India. J. American Mosquito Control Associ., 24, 6-10 (2008)
Leisnham, P.T. and S.S. Mohapatra : Mosquitoes associated with ditchplugged and control tidal salt marshes on the Delmarva Peninsula. Inter. J. Environ. Res. Pub. Hlth., 8, 3099-3113 (2011)

Luis, M., R. Luis, G.C. Luis and F. Chaves: Mosquito (Diptera: Culicidae) species composition in ovitraps from a mesoamerican tropical montane cloud forest. J. Med. Entomol., 56, 491-500 (2019)

Medlock, J.M., K.R. Snow and S. Leach: Potential transmission of West Nile virus in the British Isles: An ecological review of candidate mosquito bridge vectors. Medical Vete. Entomo., 19, 2 -21 (2005)

Padmakumar, K.G. : Kuttanad-Global Agricultural Heritage, Promoting Uniqueness. Proceeding of Kerala Environmental Congress, pp. 62-72 (2013)

Ramasamy, R., S.N. Surendran, P.J. Jude, S. Dharshini and M. Vinobaba: Larval development of Aedes aegypti and Ae. albopictus in peri-urban brackish water and its implications for transmission of arboviral diseases. Neglected Tropical Dise., 5, 1369 (2011) doi: 10.1371/journal.pntd.0001369.

Ramasamy, R. and S.N. Surendran : Global climate change and its potential impact on disease transmission by salinity-tolerant mosquito vectors in coastal zones. Frontiers Physiol., 3, (2012) doi: $10.3389 /$ fphys. 2012.00198

Ray, S. and A. Choudhury : Salinity tolerance of Culex sitiens Wied (Diptera: Culicidae) larvae in laboratory conditions. Curr. Sci., 57,159-160 (1988)

Schie, C., H. Spafford, S. Carver and P. Weinstein : Salinity tolerance of Aedes camptorhynchus from two regions in southwestern Australia. Australian J. Entomo., 48, 293-299 (2009)

Sundaresan, J., L.K. Patel and K.S. Krishnan : Climate change impact-A novel, initiative for Kerala. Indian J. Geo-Marine Sci., 40, 483-486 (2011)

Surendran, S.N., P.J. Jude, V. Thabothiny, S. Raveendran and R. Ramasamy: Pre-imaginal development of Aedes aegypti in brackish and fresh water urban domestic wells in Sri Lanka. J. VectorEcol., 37,471-473 (2012)

Thenmozhi, V., R. Paramasivan, P. P. Samuel, T. Kamaraj, T. Balaji, K.J. Dhananjeyan, K. Venkatasubramani, V.J. Leo, R.S. Babu, R. Govindarajan and B.K. Tyagi: Japanese encephalitis virus isolation from mosquitoes during an outbreak in Alappuzha district, Kerala. J. VectorBorne Dise., 50, 229-231 (2013)

Van Schie, C., H. Spafford, S. Carver and P. Weinstein: Salinity tolerance of Aedes camptorhynchus (Diptera: Culicidae) from two regions in southwesternAustralia. Australian J. Entomol., 48, 293-299 (2009)

Vaughn, D.W. and C.H. Hoke: The epidemiology of Japanese encephalitis: Prospects for prevention. Epidemio. Revi., 14, 197-221 (1992)

Yoruk, E., E.N. Keles, O. Sefer and M. Eraslan: Salinity and drought stress on barley and wheat cultivars planted in Turkey. J. Environ. Biol., 39, 943-950 (2018)

Zalizniak, L., B.J. Kefford and D. Nugeoda : Is all salinity the same? The effect of ionic compositions on the salinity tolerance of five species of freshwater invertebrates. Mari. Fresh. Res., 57, 75-82 (2006)

Zhang, J., L. Han , Y. Ji , M. Duan , G. Cai , J. Wu , W. Zhu , G. Gao, Y. Peng and Y. Zhou: Study of soil nutrients, physical and biological characteristics of paddy fields after lifting measures : A case study of China's Ganjiang region. J. Environ. Biol., 39, 432-439 (2018) 